\title{
The Incidence of Normal Coronary Angiography on Cardiac Catheterization in Jordanians
}

\author{
Ziad Khalef Drabaa and Mohammed Holy Majed \\ Adult Cardiology Department/ Queen Alia Heart Institute/ King Hussein Medical \\ Center/Jordan
}

\begin{abstract}
Objective: To determine the incidence of normal coronaries on cardiac catheterization and its pattern of occurrence according to sex and age.

Methods: This is a retrospective study conducted at Queen Alia Heart Institute in AmmanJordan during the period 2006 to 2011. A total number of 5000 adult patients who had coronary angiography for chest pain, which were reviewed looking for the presence of normal coronaries, its frequency among males and females and its occurrence according to age groups.
\end{abstract}

Results: The overall incidence of normal coronaries on cardiac catheterization was $17.3 \%$, with almost equal ratios for males and females (53.9\% and $46.1 \%$ respectively). Women in the age group 50 - 59 years was the commonest category (33.7\%) to have normal coronary angiography, whereas the commonest age group for males was 40 to 49 years. Patients above 70 years of age were very less commonly to have normal coronaries (only in $8.5 \%$ ).

Conclusion: Normal coronaries on cardiac catheterization is a recognized finding in both men and women. Recognition of this issue is essential in order to prescribe proper follow up and appropriate medical therapy with correction of modifiable risk factors.

\section{Introduction}

Coronary angiography offers clinicians both diagnostic and therapeutic opportunities

as heart disease is the commonest cause of death over all the world, and coronary angiography is the standard for detection of coronary artery disease. (Minino et al.,2007) Many patients undergoing angiography are found to have normal coronary arteries. Phibbs et al.,1988)

In spite of efforts to optimize patient selection for cardiac catheterization depending

on the clinical history, results of biochemical blood tests and stress testing, the

ratio of normal coronary angiography ranges from 10 to $20 \%$, more in women than in

\section{men. (Jong et al.,1996)}

Normal angiography on cardiac catheterization in patients with chest pain is still a

recognized finding and five times more common in women than in men. Sullivan et al.,1994 \& Abdelmoneim et al., 2009)

Some forms of ischemic chest pain may be caused by abnormalities of the microcirculatory vessels (Cannon et al.,1988) other causes for chest pain and normal coronary angiography may be due to endothelium abnormality with consequent spasm. ( Nabel et al,1988)

Although acute myocardial infarction is generally associated with significant coronary

artery disease, it was reported to occur in patients with normal coronary angiography. (Sharifi et al,1995)

Patients with normal coronaries should not be denied treatment and proper 
management of risk factors as the natural follow up course of these patients suggests that there is a significant risk for death and development of coronary artery disease. ( Jason et al,2011 \& Bugiardini et al, 2006 )

\section{Methods:}

This retrospective study was conducted at Queen Alia Heart Institute in

Amman - Jordan, during the period January 2006 to January 2011.

The sample size involved 5000 adult patients (>18 years) who underwent coronary

angiography in that period of time, for mainly chest pain.

Patients known to have congenital structural heart disease or valvular heart disease

were excluded from the study, pediatric age group was not involved as well. Patients

found to have coronary ectasia were not considered as normal angiography.

Review of all records was done looking for the documentation of normal coronary

arteriography in each case. The study was designed to determine the overall incidence

of normal coronaries on cardiac catheterization in patients with chest pain, and

its frequency in males and females.

\section{Results:}

As can be seen in table 1, normal coronaries were found in 864 cases, in a ratio of

$17.3 \%$ of the total number of the studied angiograms.

Males and females constituted almost a similar participation in this ratio; about a half

for each (53.9\% and $46.1 \%$ respectively).

Table 2 shows the distribution of normal coronaries in respect to different age groups

in both men and women, with the commonest $(33.7 \%)$ found in females aged between
50 and 59 years.

The next common category (31.4\%) with normal coronaries was females in the age group 60 - 69 years, followed by males aged $40-49$ years in a ratio of $30.3 \%$. The commonest overall (men and women) ratio was $28.6 \%$ and it was found in the age group 50-59 years.

The finding of normal coronaries on cardiac catheterization was rare $(2.1 \%)$ below the

age of 30 years, and it was uncommon $(8.5 \%)$ above the age of 70 years.

\section{Discussion:}

The overall incidence of normal coronaries in our study is $17.3 \%$, which is similar to the rate reported in the medical literature. (Phibbs et al.,1988 \& Mahrer et al., 1981 )

However, the ratio is variable with a higher rate in some studies ${ }^{\text {(Jason et al.,2011) }}$ and a lower rate in others. (Alejandro et al.,2009)

The differences in the incidence of normal coronaries on cardiac catheterization between studies might be explained by the different characteristics of the population studied, besides, it could depend on the criteria of the involved patients, like the presence or absence of cardiac biomarkers and whether or not electrocardiographic (ECG) ischemic changes were considered.

We believe, the incidence of normal coronaries should be higher than the ratio occurred in this trial, as a considerable number of patients with normal coronaries were not involved in the study sample, but had their cardiac catheterization for valvular heart disease and before going to valve surgery. In addition, patients with only coronary ectasia and without coronary plaques were not considered normal.

Although a normal coronary finding was reported to be much more commoner in females than in males, ( Sullivan et al.,1994 \& Abdelmoneim et al., 2009 \& Alejandro et al.,2009) the ratio obtained in our study was almost equal in men and women. This may reflect the 
selective basis of referral for cardiac catheterization and coronary angiography and may be due to the recent change in the seriousness of the symptom of chest pain when it occurred in women.

Currently, attention should be shifted to other proven modalities in the diagnosis of coronary artery status before going to the invasive coronary arteriography, especially in low risk people who are expected to be normal or near normal coronaries. For example, computed tomography $(\mathrm{CT})^{(\text {Zeina et al,2007) }}$ scan and magnetic resonance angiography (MRA) Mavrogeni et al,2004) which proved its usefulness in demonstrating the presence and the extent of coronary artery disease, in addition to allow a great accuracy in the diagnosis of atherosclerosis and stenosis in those vessels.
Normal coronaries in patients with recurrent chest pain should not be considered a

benign issue, as acute myocardial infarction can occur on top of normal coronaries (Bugiardini et al, 2006 \& Antman et al,2000) and in fact, it was reported that $2 \%$ of patients with normal coronaries and recurrent chest pain die within one year of their admission. ${ }^{\text {Bugiardini } \text { et al, 2006) }}$

In addition, in a five - year follow up for patients with normal coronaries, it was documented that this group of patients at significant risk for death and development of coronary artery disease. ( ${ }^{\text {(ason et al,2011) }}$

Recognition of this issue is essential in order to prescribe proper follow up and appropriate medical therapy with correction of modifiable risk factors.

Table I

Overall incidence of normal coronary arteriography and according to sex

\begin{tabular}{|c|c|c|c|}
\hline Total & $\begin{array}{l}\text { No. of patients with } \\
\text { normal coronaries }\end{array}$ & No. of males & No. of females \\
\hline 5000 & 864 & 466 & 398 \\
\hline$\%$ & $17.3 \%$ & $53.9 \%$ & $46.1 \%$ \\
\hline
\end{tabular}

Table II

Distribution of normal coronaries according to sex and different age groups

\begin{tabular}{|c|c|c|c|}
\hline Age group (years) & No. of males (\%) & No. of females (\%) & Total (\%) \\
\hline $18-29$ & $18(3.9 \%)$ & $0(0.0 \%)$ & $18(2.1 \%)$ \\
\hline $30-39$ & $97(20.8 \%)$ & $19(4.8 \%)$ & $116(13.4 \%)$ \\
\hline $40-49$ & $141(30.3 \%)$ & $77(19.3 \%)$ & $218(25.2 \%)$ \\
\hline $50-59$ & $113(24.2 \%)$ & $134(33.7 \%)$ & $247(28.6 \%)$ \\
\hline $60-69$ & $67(14.4 \%)$ & $125(31.4 \%)$ & $192(22.2 \%)$ \\
\hline$\geq 70$ & $30(6.4 \%)$ & $43(10.8 \%)$ & $73(8.5 \%)$ \\
\hline Total & $466(100 \%)$ & $398(100 \%)$ & $864(100 \%)$ \\
\hline
\end{tabular}





\section{References}

Minino AM, Heron MP, Murphy SL, Kochanek KD. (2007) :Centers for disease control and prevention national center for health statistics national vital statistics system. Deaths: final data for 2004 . Natl Vital Stat Re55:1 -119.

Phibbs B, Fleming T, Ewy GA, Butman S, Ambrose J, Gorlin R. (1988): Frequency of normal coronary arteriograms in three academic medical centers and one community hospital. Am J Cardiol 62:472 474.

Jong P, Mohammed S, Sternberg L (1996): Sex differences in the features of coronary artery disease of patients undergoing coronary angiography. Can J Cardiol 12:671 $-677$.

Sullivan AK, Holdright DR, Wright CA, Sparrow JL, Cunningham D.(1994): Chest pain in women: clinical, investigative, and prognostic features. . BMJ 308:883 -886.

Abdelmoneim AA, Ahmed SA,Mohamed A (2009): Angiographic coronary artery anatomy in the Sudan Heart Centre. . Khartoum Medical Journal;2:162 - 164.

Cannon RO, Epstein SE (1988): Microvascular angina as a cause of chest pain with angiographically normal coronary arteries. . Am J Cardiol;61:1338-1343.

Nabel EG, Ganz P, Gordon JB, Alexander RW, Selwyn AP (1988): Dilation of normal and constriction of atherosclerotic coronary arteries caused by the cold pressor test. Circulation;77:43 - 52.

Sharifi M, Frohlich TG, Silverman IM (1995): Myocardial infarction angiographically normal coronary arteries. Chest; 107:36 - 40 .

Jason T, Christopher J, Andra L (2011): Five year mortality and coronary heart disease development after normal coronary angiogram. World J Emerg Med ;2:24 - 29.

Bugiardini R, Manfrini O, De Ferrari GM (2006): Unanswered questions for management of acute coronary syndrome. Risk stratification of patients with minimal disease or normal coronary angiography. Arch Int Med ;166:1391 - 1395.

Mahrer PR, Eshoo N. (1981): Outpatient cardiac catheterization and coronary angiography. Cathet Cardiovasc Diagn;7:355 -360 .

Alejandro C, Juan S, Vicente B, Julio N, Luis M, Mauricio P, Gema M, Enrique S, Eloy D, Patricia P, Angel L. (2009): Non - ST Elevation acute myocardial infarction with normal coronary arteries: predictors and prognosis. Rev Esp Cardiol ;62:1260 - 1266. Zeina AR, Sharif D, Blinder J, Rosenschein U, Barmeir E. (2007): Noninvasive assessment of coronary artery ectasia using multidetector computed tomography. Coron Artery Dis ; 18:175-180.

Mavrogeni SI, Manginas A, Papadakis E, Foussas S, Douskou M, Baras P, Seimenis I, Cokkinos DV . (2004): Correlation between magnetic resonance angiography (MRA) and quantitative coronary angiography (QCA) in ectatic coronary vessels. $J$ Cardiovasc Magn Reson ;6: 17-23.

Antman EM, Cohen M, Bernink PJ. (2000): The TIMI risk score for unstable angina / non - ST elevation MI: a method for prognostication and therapeutic decision making. JAMA ;284:835 - 842. 


\title{
احتمالية تصوير الثرايين الطبيعية بواسطة القسطرة القلبية في المجتمع الأردني
}

\author{
زياد خلف الضرابعة و محمد هولي ماجد \\ مركز الملكة علياء لأمر اض وجر و احة القلبـالأردن
}

هدف الدر اسة وملخصها: - مل

تصوير الثر ايين الطبيعية بواسطة القسطرة القلبية وتحديد نمط الثرايين حسب العمر

$$
\text { و الجنس. }
$$

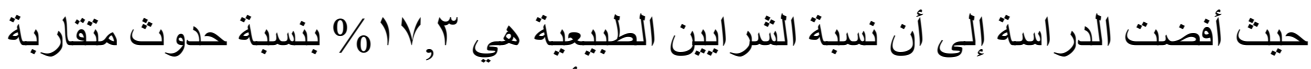

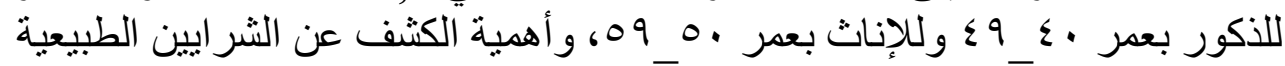

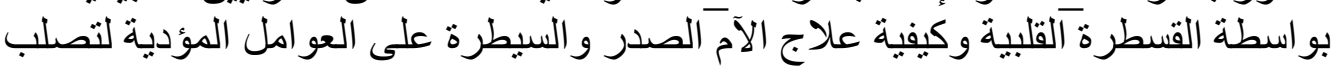

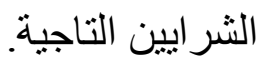

